\title{
PRIMERA DESCRIPCIÓN DEL DESARROLLO LARVAL TEMPRANO DE LA VIEIRA PATAGÓNICA (Zygochlamys patagonica)
}

\author{
Matías Schwartz ${ }^{1}$ y Silvana CAmpodónico \\ Instituto Nacional de Investigación y Desarrollo Pesquero (INIDEP), \\ Paseo Victoria Ocampo No 1, Escollera Norte, B7602HSA - Mar del Plata, Argentina \\ ${ }^{1}$ correo electrónico: schwartz@inidep.edu.ar
}

\begin{abstract}
RESUMEN. Se procedió a describir el desarrollo larval temprano de la vieira patagónica (Zygochlamys patagonica) que se obtuvo de los desoves de las temporadas de verano 2015 y 2017. Los desoves se obtuvieron por inducción con las técnicas de limpieza valvar y shock térmicos $\left(7\right.$ y $\left.13^{\circ} \mathrm{C}\right)$ en 16 vieiras adultas de entre 55 y $72 \mathrm{~mm}$ de alto de valva, sexualmente maduras y en igual proporción de sexos. El agua de los recipientes de inducción se filtró con tamiz de $35 \mu \mathrm{m}$ para retener los ovocitos fecundados que se colocaron en recipientes de 21 con agua oceánica a $7 \pm 0,5^{\circ} \mathrm{C}$ y $\sin$ aireación. Se observaron y midieron los estadios de desarrollo temprano hasta larva trocófora y se registró la duración de cada fase y el tipo de movimiento. El desarrollo embrionario se completó con el estadio de gástrula 30-40 h posteriores a la fecundación. La fase de larva trocófora comenzó a las 80-84 h, estadio en que se produjo la mortalidad total de las larvas. Si bien no se completó el ciclo de vida de Z. patagonica, el presente trabajo constituye el primer registro de desarrollo larval temprano de la especie, necesario para conocer el tiempo que la larva pasa en la columna de agua y, por lo tanto, su capacidad de dispersión.
\end{abstract}

Palabras clave: Larvas, desarrollo, vieira patagónica, Argentina.

\section{FIRST DESCRIPTION OF PATAGONIAN SCALLOP (Zygochlamys patagonica) EARLY LARVAL DEVELOPMENT}

\begin{abstract}
Description of Patagonian scallop (Zygochlamys patagonica) early larval development observed in the 2015 and 2017 Summer seasons spawning was made. Spawning was obtained through induction with the valval cleaning and thermal shocks $\left(7\right.$ and $13^{\circ} \mathrm{C}$ ) techniques in 16 adult scallops $55-72 \mathrm{~mm}$ shell height, sexually mature and in equal sex proportion. The water of the induction vessels was filtered with a $35 \mu \mathrm{m}$ sieve to retain the fertilized oocytes that were placed in 21 containers with ocean water at $7 \pm 0,5^{\circ} \mathrm{C}$ and without aeration. Early development stages up to trochophore larva were observed and measured and the duration of each phase and type of movement registered. The embryonic development was completed with the gastrula stage 30-40 h post fertilization. The trochophore larva phase started at 80-84 h, stage during which total mortality of larvae occurred. Although Z. patagonica life cycle was not completed, this work constitutes the first registry of the species early larval development, necessary to know the time the larva spends in the water column and, thus, its dispersion capacity.
\end{abstract}

Key words: Larvae, development, Patagonian scallop, Argentina. 


\section{INTRODUCCIÓN}

Dentro de los moluscos bivalvos se encuentra la Familia Pectinidae, conocidos comúnmente como vieiras, los cuales poseen un gran valor comercial debido a sus altas densidades y su calidad alimenticia (Peña 2001; Orensanz et al. 2013; Duncan et al. 2016; Stokesbury et al. 2016). Si bien estos moluscos son organismos de hábito bentónico, encontrándose apoyados sobre el fondo o fijos a un sustrato (por ejemplo, Chlamys varia, en Hily y Le Foll 1990), su desarrollo larval es planctónico.

Dentro de las especies de vieira podemos encontrar distintos tipos de ciclos de vida, desarrollo indirecto con larva veliger lecitotrófica o planctotrófica, o directo con cuidado parental, siendo el desarrollo indirecto con larva planctotrófica nadadora el más común (Cragg 2016). Este ciclo indirecto posee un desarrollo larval con diferentes estadios característicos para cada especie y está relacionado con factores tales como la temperatura, profundidad y disponibilidad de alimentos que afectan los tiempos de duración de los distintos estadios (Cragg 2016).

El desarrollo larvario indirecto en pectínidos puede dividirse en tres fases: a) una fase lecitotrófica con embrión y larva temprana nutriéndose de reservas vitelinas del ovocito, b) fase mixotrófica donde las larvas utilizan las últimas reservas vitelinas y también se alimentan con fitoplancton, c) fase planctotrófica con alimentación exclusivamente de microorganismos y detritos (Roman et al. 2001a).

La pesquería de vieira patagónica (Zygochlamys patagonica) en aguas de la plataforma continental argentina comenzó en 1996, luego de que distintos cruceros de investigación confirmaran la existencia de grandes concentraciones potencialmente explotables (Lasta y Bremec 1998). Desde que se iniciara esta pesquería, la vieira patagónica ha constituido un recurso de gran importancia comercial. Durante 2015, los desembarques declarados de callo (músculo abductor) fueron de 4.404 t (Campodónico y Herrera 2016), siendo los principales mercados Francia, Estados Unidos y Canadá, con un precio promedio de 11.041 dólares la tonelada (Ministerio de Agroindustria 2016).

Esta especie es característica de aguas templado-frías y se distribuye en el Océano Atlántico desde el Cabo de Hornos (55 56' S) hasta la latitud del Río de la Plata ( $\left.35^{\circ} 50^{\prime} \mathrm{S}\right)$, formando agregaciones o bancos entre los 70 y $100 \mathrm{~m}$ de profundidad (Lasta y Zampatti 1981; Bogazzi et al. 2005). Su distribución coincide con sistemas frontales representados como áreas de transición entre las aguas de plataforma y la Corriente de Malvinas (Martos y Piccolo 1988), los cuales se caracterizan por tener productividades biológicas y retenciones larvales altas (Acha et al. 2004).

$Z$. patagonica es una especie dioica cuyo ciclo reproductivo es de tipo estacional, con desoves parciales desde la primavera hasta fines del verano (Campodónico et al. 2008). Al igual que la mayoría de los bivalvos, presenta un ciclo de vida con una fase planctónica y otra bentónica. Durante la fase planctónica se produce la dispersión larval entre y dentro de los bancos, en la que operan mecanismos de transporte horizontales por medio de corrientes marinas (Tremblay y Sinclair 1988, 1992; Gosling 2003; Le Pennec et al. 2003), y movimientos ascendentes y descendentes producto de los solapamientos de corrientes que se producen en el borde del talud (Matano y Palma 2008; Franco et al. 2017). El desarrollo larval en $Z$. patagonica es del tipo planctotrófico (Schejter et al. 2010) inferido a partir del radio entre disoconcha I y II en juveniles recientemente asentados, sin embargo los estadios y tiempos larvales tempranos aún son desconocidos.

El objetivo de este estudio fue determinar las características morfológicas de los distintos estadios del desarrollo larvario de Z. patagonica. Conocer el desarrollo temprano de vida es de suma importancia para determinar el tiempo que 
transcurre en la columna de agua la larva de la vieira patagónica, el cual es necesario para definir su capacidad de dispersión y el momento de su asentamiento.

\section{MATERIALES Y MÉTODOS}

Los reproductores de vieira patagónica se recolectaron en bancos naturales en enero de 2015 $\left(42^{\circ} 23^{\prime} \mathrm{S}\right.$ y $59^{\circ} 03^{\prime} \mathrm{W}$, profundidad $\left.110 \mathrm{~m}\right)$ y

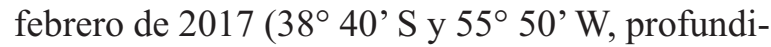
dad $94 \mathrm{~m}$ ), época en la cual esta especie se encuentra reproductivamente madura. El estado de madurez fue determinado mediante un examen macroscópico según la forma y color de la gónada (Campodónico et al. 2008).

Durante su traslado al laboratorio se acondicionaron los reproductores de forma tal de evitar estrés en los mismos (Schwartz et al. 2016). Una vez en el laboratorio, las vieiras fueron colocadas en sistemas de cultivo con recirculación conformado por un espumador y filtro biológico con capacidad de 300 1. El agua de mar fue tratada previamente con filtros de arena. Los animales se mantuvieron en oscuridad total y reposo sin alimentación durante $48 \mathrm{~h}$.

Dos experiencias se realizaron para obtener desoves de vieiras sexualmente maduras. En la primera, los organismos recolectados en 2015 (N =16) fueron sometidos a distintos métodos de inducción al desove utilizados comúnmente en pectínidos. En la segunda experiencia, los reproductores recolectados en $2017(\mathrm{~N}=20)$, desovaron espontáneamente en los acuarios del laboratorio durante su acondicionamiento.

Para la Experiencia 1, las inducciones fueron realizadas por los métodos de limpieza valvar y shock térmico con individuos de valva mayor o igual a $55 \mathrm{~mm}(64,4 \pm 4,1)$ e igual proporción de sexos (8 machos: 8 hembras). Las vieiras de ambos sexos fueron colocadas juntas en bandejas plásticas de $50 \times 30 \times 10 \mathrm{~cm}$ con agua de mar oceánica sin filtrar recolectada durante las campañas de evaluación de vieira patagónica. Estas bandejas con poco volumen de agua permiten un cambio rápido de temperatura y una buena observación del inicio de los desoves. Cabe mencionar que los ejemplares se encontraban maduros al llegar al laboratorio, por lo que no fue necesario un acondicionamiento de maduración.

Previo a la inducción al desove, se procedió a la limpieza de las valvas para la extracción de los epibiontes (esponjas, cnidarios, poliquetos, etc.) que se encuentran sobre ellas mediante el frotado con un cepillo. Posteriormente, los ejemplares fueron inducidos al desove mediante estimulación térmica, siendo sometidos a cambios bruscos de temperatura alternando baños de agua aclimatada por períodos de $1 \mathrm{~h}$ y de forma repetida durante $4 \mathrm{~h}$, para lo cual una bandeja se mantuvo a $7{ }^{\circ} \mathrm{C}$ y otra se calentó a $13{ }^{\circ} \mathrm{C}$. Finalizados los baños térmicos, las bandejas con las vieiras en su interior se dejaron en reposo dentro de la cámara de temperatura controlada a $7{ }^{\circ} \mathrm{C}$, sin aireación y en oscuridad. Alcanzadas las $24 \mathrm{~h}$ posteriores a los tratamientos de inducción, el agua de las bandejas donde se encontraban los reproductores fue filtrada con un tamiz de $35 \mathrm{~mm}$ de malla, el cual fue utilizado para retener los ovocitos (fecundados y no fecundados).

En la Experiencia 2, se filtró el agua de los tanques donde eran mantenidos los reproductores $(62,4 \pm 5,1 \mathrm{~mm}$, largo valvar) con malla de 35 $\mathrm{mm}$. En esta ocasión desoves ocurrieron espontáneamente. En ambas experiencias, los ovocitos obtenidos se traspasaron a recipientes de 21 , con recambios del $100 \%$ por agua oceánica cada $24 \mathrm{~h}$. El desarrollo larval se llevó a cabo en estos recipientes bajo condiciones de oscuridad, sin alimentación ni aireación, con una salinidad de $35 \mathrm{y}$ a una temperatura de $7,0 \pm 0,5^{\circ} \mathrm{C}$. La aparición de cada fase de desarrollo fue controlada tomando alícuotas de $1 \mathrm{ml}$ cada 1 y $4 \mathrm{~h}$ durante la fase embrionaria y larval, respectivamente. Las observaciones y mediciones de los distintos estadios fueron realizadas in vivo con microscopio óptico 
con ocular graduado, fotografiando los estadios con una cámara digital Olympus DP71. Para la descripción de las fases de desarrollo se utilizó la metodología descriptiva estándar para moluscos pelecípodos según Sastry (1979).

\section{RESULTADOS}

Finalizadas las inducciones, los reproductores desovaron simultáneamente observándose en el agua un color blanco característico de la liberación de espermatozoides, mientras que, junto a las hembras, se observó un color anaranjado de los ovocitos desovados. Los ovocitos se hidrataron dentro de los $30 \mathrm{~min}$ posteriores al desove, adquiriendo una forma esférica con membrana vitelina (Figura $1 \mathrm{~A})$ y diámetro promedio de $65,87 \pm 8,83 \mathrm{~mm}$ (Tabla 1). La formación del cigoto fue reconocida por la eliminación del corpúsculo polar producto de las reducciones meióticas, las cuales ocurrieron 1-2 h después de producida la fecundación. Una vez reconocida la fecundación, el agua de las bandejas se filtró con malla de $35 \mathrm{~mm}$. Seguido a la liberación del corpúsculo polar se observó la primera, segunda y tercera división celular donde se pudieron dife-
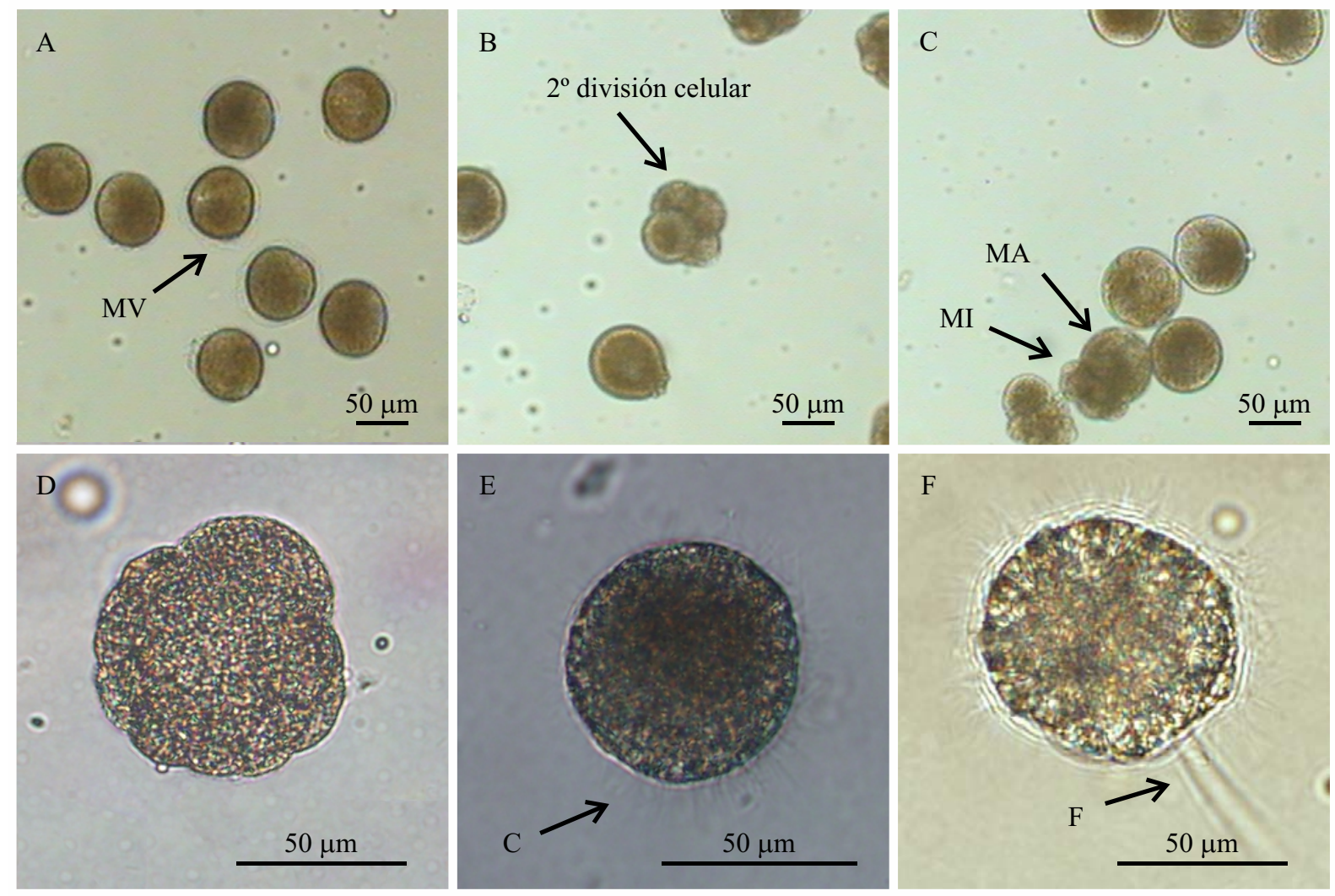

Figura 1. Desarrollo embrionario y larval temprano de Zygochlamys patagonica. A) Ovocitos maduros, MV: membrana vitelina. B) Segunda división celular, 4 células. C) Tercera división celular, 8 células, MA: macrómero, MI: micrómero. D) Mórula. E) Gástrula ciliada, C: cilios. F) Larva trocófora, F: flagelo.

Figure 1. Zygochlamys patagonica early embryonic and larval development. A) Mature oocytes, MV: vitelline membrane. B) Second cell cleavage, 4 cells. C) Third cell cleavage, 8 cells, MA: macromere, MI: micromere. D) Morula. E) Ciliated gastrula, C: cilia. F) Trochophore larva, F: flagellum. 
Tabla 1. Estadios embrionarios y de larva trocófora de Zygochlamys patagonica. Tiempo de aparición y tallas de los estadios postfecundación.

Table 1. Zygochlamys patagonica embryonic and trochophore larva stages. Appearance time and sizes of post fertilization stages.

\begin{tabular}{lccr}
\hline Estadio & $\begin{array}{c}\text { Tiempo } \\
\text { postfertilización (h) }\end{array}$ & $\begin{array}{c}\text { Talla (mm) } \\
\text { Promedio } \pm \mathrm{DE}\end{array}$ & $\mathrm{N}$ \\
\hline Ovocito & - & $65,87 \pm 8,83$ & 30 \\
Cigoto & $>1$ & - & \\
Eliminación del corpúsculo polar & $1-2$ & - & 30 \\
Mórula & $12-16$ & $64,57 \pm 8,90$ & - \\
Blástula & 18 & $66,67 \pm 5,29$ & 30 \\
Gástrula & $30-40$ & $76,89 \pm 5,63$ & 5 \\
Larva trocófora & $80-84$ & & \\
\hline
\end{tabular}

renciar células de menor (micrómeros) y mayor tamaño (macrómeros), producto de una segmentación holoblástica desigual (Figura 1 B y C).

Después de las $12 \mathrm{~h}$ de producida la fecundación se observó la primer mórula (Tabla 1) en la cual los micrómeros cubren casi la totalidad del embrión (Figura 1 D). Luego de 30 h de producida la fecundación (Tabla 1) se visualizaron las primeras gástrulas con cilios bien definidos (Figura $1 \mathrm{E}$ ) y diámetro promedio de $66,67 \pm 5,29 \mathrm{~mm}$ (Tabla 1), con movimientos rotatorios característicos de este estadio.

La primera larva trocófora se registró a las $80 \mathrm{~h}$ postfecundación con un diámetro de $76,89 \pm$ $5,63 \mathrm{~mm}$ (Tabla 1), exhibiendo una forma circular con cilios más desarrollados que los vistos en las gástrulas y con un par de flagelos de longitud similar al diámetro total de la larva (Figura $1 \mathrm{~F}$ ). Durante esta fase, las larvas presentaron una natación rotacional y de traslación vigorosa, conducida por los flagelos apicales. Si bien no se produjeron cambios en las condiciones en que se desarrollaron los estadios descriptos, ocurrió la mortalidad total de las larvas trocóforas dentro de las $18 \mathrm{~h}$ posteriores a su formación, motivo por el cual no fue posible conocer los estadios larvales siguientes.

\section{DISCUSIÓN}

Este trabajo constituye el primer registro del desarrollo larval temprano hasta larva trocófora en Z. patagonica. Debido a la mortalidad total producida durante la fase larval de trocófora no fue posible identificar los estadios larvales subsiguientes. Cabe aclarar que los pectínidos tienen en general porcentajes muy altos de mortalidad durante su desarrollo embrionario y larval (Culliney 1974; Taylor et al. 1993; Navarte y Pascual 2003), siendo la fase larvaria de trocófora la más crítica debido a su cuerpo desnudo (sin valvas), lo que la hace más vulnerable a los agentes patógenos como virus y bacterias (Uriarte et al. 2001).

Si bien aún se desconoce el desarrollo larvario completo de la vieira patagónica, existen diagramas sobre el ciclo de vida de pectínidos que ayudan a comprender como podrían ser los distintos estadios aún no identificados para esta especie. El diagrama de Le Pennec et al. (2003), plantea un ciclo de vida tipo para pectínidos, el cual se utilizó en este trabajo como referencia para señalar los estadios de Z. patagonica (Figura 2). En dicho diagrama se pueden observar los posibles esta- 
dios larvales consecutivos a la larva trocófora de la vieira patagónica.

El desarrollo embrionario y la aparición de la larva trocófora determinados en este trabajo para $Z$. patagonica son consistentes con lo observado para otras especies de pectínidos de diversas latitudes, como en la vieira antártica Adamussium colbecki (Peck et al. 2007), Placopecten magella- nicus de América del Norte (Desrosiers et al. 1996) o la vieira tropical Nodipecten nodosus (De la Roche et al. 2002). El tiempo desde la fecundación hasta la formación de la larva trocófora ( $80-84 \mathrm{~h}$ ) en la vieira patagónica es mayor al de otras especies de vieira (Tabla 2), donde la baja temperatura de los acuarios del presente trabajo, que es la misma que tiene esta especie en su

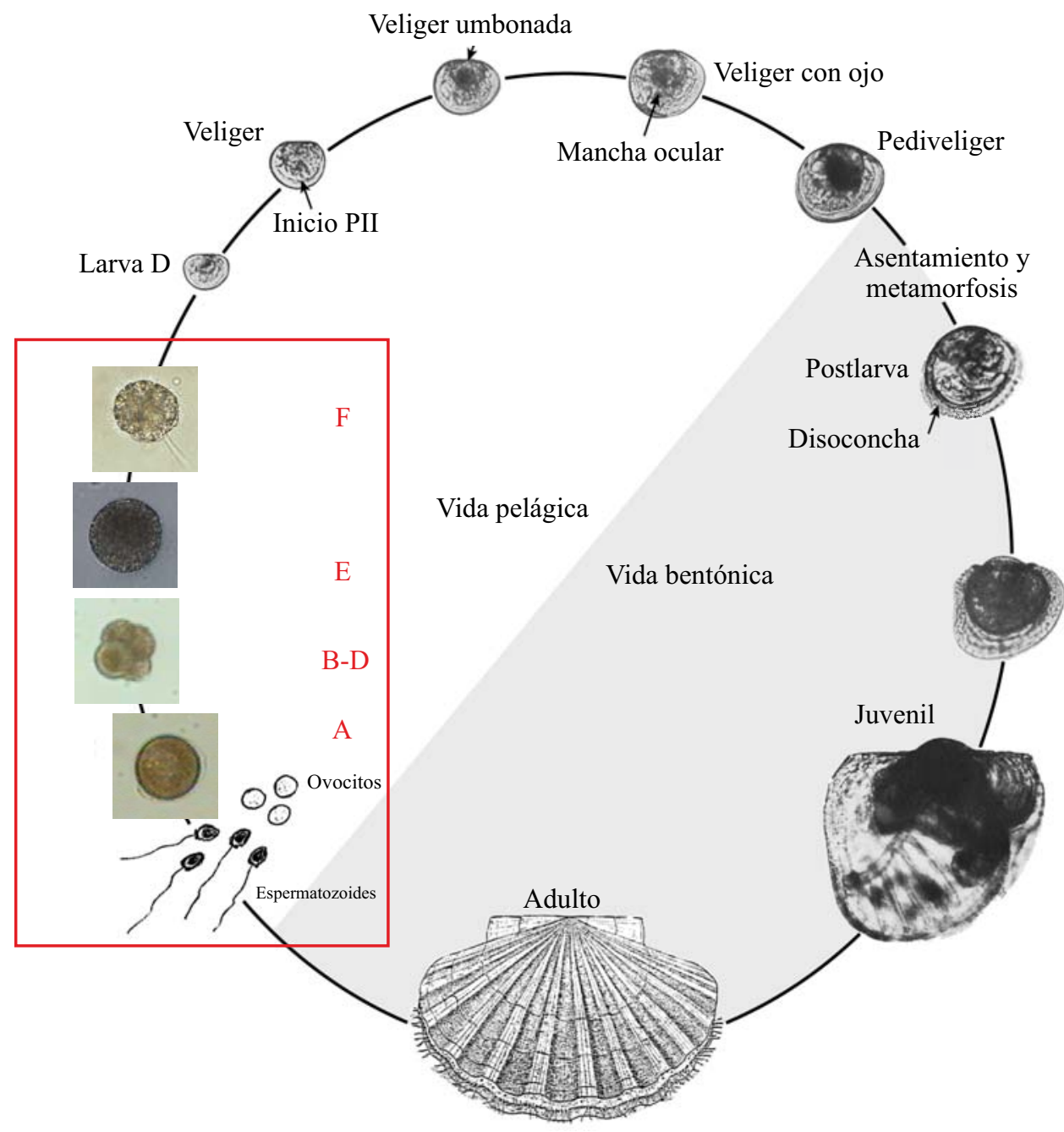

Figura 2. Diagrama del ciclo de vida del pectínido Pecten maximus (tomado de Le Pennec et al. 2003). El recuadro representa los estadios embrionarios y larvales determinados en el presente trabajo. A: ovocitos maduros, B-D: primeras divisiones celulares, E: gástrula, F: larva trocófora.

Figure 2. Diagram of the Pecten maximus pectinid life cycle (taken from Le Pennec et al. 2003). The box represents the embryonic and larval stages determined in this work. A: mature oocytes, B-D: first cells cleavage, E: gastrula F: trochophore larva. 
Tabla 2. Tiempo (h) del desarrollo temprano de estadios embrionarios y larval en pectínidos cultivados en laboratorio. Table 2. Time (h) of embryonic and larval stages early development in pectinids cultured in laboratory.

\begin{tabular}{lccccl}
\hline Especie & Temperatura $\left({ }^{\circ} \mathrm{C}\right)$ & Blástula (h) & Gástrula (h) & Trocófora (h) & \multicolumn{1}{c}{ Referencia* } \\
\hline Zygochlamys patagonica & 7 & 18 & $30-40$ & $80-84$ & Presente estudio \\
Adamussium colbecki & 0,9 & 90 & - & 177 & Peck et al. (2007) \\
Mizuhopecten yessoensis & 13 & - & - & 84 & Pyen y Rho (1978) \\
Pecten meridionalis & 14 & - & - & 48 & Dix y Sjarolin (1975) \\
Pecten maximus & 15 & 12 & - & 24 & Comely (1972) \\
Amusium balloti & 18,5 & 7 & 16 & 28 & Rose et al. (1988) \\
Spondylus tenebrosus & 23 & 4 & 6 & 11 & Parnell (2002) \\
Argopecten irradians & 24 & 5 & 9 & 24 & Sastry (1965) \\
\hline
\end{tabular}

*Tomado de Peck et al. 2007.

medio natural, podría ser la responsable de las diferencias en los tiempos de desarrollo. Al respecto, Beamount y Barnes (1992) analizaron cómo la temperatura afectaba el tiempo de desarrollo larval de la vieira del Atlántico Norte Pecten maximus, registrando un aumento en el tiempo de desarrollo con la disminución de la temperatura. Se observa en la Tabla 2 cómo la temperatura de cultivo estaría relacionada inversamente al tiempo en las etapas de desarrollo, donde la vieira antártica $A$. colbecki cultivada a $0,9{ }^{\circ} \mathrm{C}$, presentó un tiempo de desarrollo hasta 18 veces mayor al de especies de pectínidos subtropicales (Peck et al. 2007).

Durante la vida planctónica de las larvas de vieira se producen cambios morfológicos que posibilitan el movimiento en la columna de agua y su capacidad de dispersión, los cuales varían según la especie y las condiciones ambientales (Román et al. 2001b). Cuando la larva comienza a alimentarse (larva veliger) realiza migraciones en la columna de agua nadando hacia arriba y dejándose caer, siendo las corrientes laterales las que producen la dispersión de las larvas (Le Pennec et al. 2003; Cragg 2016).

Si bien en este trabajo se logró el reconocimiento estructural de los estadios embrionarios y de la larva trocófora en Z. patagonica, sería importante determinar las características de las fases subsiguientes (tiempo que transcurre cada estadio, tipo y forma de nado, etc.), las cuales son relevantes para establecer el tiempo que la larva permanece en la columna de agua, período en el cual los organismos son pasibles de ser transportados hasta el momento de asentamiento al sustrato. Estos datos empíricos son necesarios para correr modelos de simulación que acoplan variables físicas y biológicas. La simulación de la dispersión larvaria por estos modelos puede ser utilizada en la pesquería de Z. patagonica para comprender las fluctuaciones que se producen en los reclutamientos (Franco et al. 2015, 2017).

El acondicionamiento en laboratorio de individuos de Z. patagonica hasta alcanzar su maduración facilita la obtención de desoves de forma controlada y continua, evitando depender de las épocas de desove en el medio natural, así como los problemas que acarrean su búsqueda y traslado hasta el laboratorio. Para esto, es necesario conocer las condiciones físicas (temperatura, luz), químicas (salinidad, amoniaco, nitrato) y nutricionales (concentración y especies de microalgas) óptimas para lograr la maduración de $Z$. patagonica en laboratorio. 
Desde el "Programa Pesquerías de Moluscos Bentónicos" del Instituto Nacional de Investigación y Desarrollo Pesquero (INIDEP) se continúa trabajando e investigando a fin de perfeccionar la dieta, los métodos de inducción al desove y las condiciones óptimas necesarias a fin de lograr una mayor supervivencia larval de $Z$. patagonica en condiciones controladas.

Contribución INIDEP Nº 2192.

\section{REFERENCIAS}

Acha EM, Mianzan HW, Guerrero RA, Favero M, BAVA J. 2004. Marine fronts at the continental shelves of South America physical and ecological processes. J Mar Syst. 44: 83-105.

BEAUMONT AR, BARNES DA. 1992. Aspects of veliger larval growth and byssus drifting of the spat of Pecten maximus and Aequipecten opercularis. ICES J Mar Sci. 49: 417-423.

Bogazzi E, BALdoni A, Rivas A, Martos P, Reta, R, ORensanz JM, Lasta M, Dell'ARCIPRETE P, WERNER F. 2005. Spatial correspondence between areas of concentration of Patagonian scallop (Zygochlamys patagonica) and frontal systems in the southwestern Atlantic. Fish Oceanogr. 14: 359-376.

CAMPODÓNICO S, HerRera S. 2016. Vieira patagónica (Zygochlamys patagonica): estadísticas de la pesquería correspondientes al año 2015. Inf Téc Of INIDEP $N^{\circ}$ 16/2016. 12 p.

Campodónico S, Macchi G, Lomovasky B, LASTA M. 2008. Reproductive cycle of the Patagonian scallop Zygochlamys patagonica in the south-western Atlantic. J Mar Biol Assoc UK. 88 (3): 603-611.

CRAGG SM. 2016. Biology and ecology of scallop larvae. En: SHUMWAY SE, PARSONS GJ, editores. Scallops: biology, ecology, acuaculture, and fisheries. Developments in Aquaculture and Fisheries Science, Vol. 40. Elsevier. p 3183.
Culliney JL. 1974. Larval development of the giant scallop Placopecten magellanicus (Gmelin). Biol Bull. 147: 321-332.

De la Roche JP, Marín B, Freites L, Vélez A. 2002. Embryonic development and post-larval growth of the tropical scallop Nodipecten (= Lyropecten) nodosus (L. 1758) (Mollusca: Pectinidae). Aquacult Res. 33: 819-827.

Desrosiers RR, Désilets J, Dubé F. 1996. Early developmental events following fertilization in the giant scallop Placopecten magellanicus. Can J Fish Aquat Sci. 53: 1382-1392.

Duncan PF, Brand AR, Strand Ø, Foucher E. 2016. The European scallop fisheries for Pecten maximus, Aequipecten opercularis, Chlamys islandica, and Mimachlamys varia. En: SHumway SE, PARSONS GJ, editores. Scallops: biology, ecology, acuaculture, and fisheries. Developments in Aquaculture and Fisheries Science, Vol. 40. Elsevier. p 781-858.

Franco BC, Palma ED, Combes V, Lasta ML. 2017. Physical processes controlling passive larval transport at the Patagonian Shelf Break Front. J Sea Res. 124: 17-25.

Franco BC, Palma ED, Tonini MH. 2015. Benthic-pelagic uncoupling between the Northern Patagonian Frontal System and Patagonian scallop beds. Estuar Coast Shelf Sci. 153: 145155.

GosLing E. 2003. Reproduction, settlement and recruitment. En: GosLing E, editor. Bivalve molluscs: biology, ecology and culture. Fishing News Books. Oxford: Blackwell Science. p. 131-168.

Hily C, Le Foll D. 1990. Distribution des supports coquilliers sur les fonds meubles infralittoarux: rôle des perturbations physiques et consequences su l'abondance et la distribution d'une population de Chlamys varia. CR Acad Sci Paris. 311: 187-192.

LASTA M, BREMEC C. 1998. Zygochlamys patagonica in the Argentine Sea: a new scallop fishery. J Shellfish Res. 17 (1): 103-111.

LASTA M, ZAMPATti E. 1981. Distribución de cap- 
turas de moluscos bivalvos de importancia comercial en el Mar Argentino. En: ANGELES$\mathrm{CU}$ V, editor. Campañas de investigación pesquera realizadas en el Mar Argentino por los B/I "Shinkai Maru" y "Walther Herwig" y el B/P "Marburg", años 1978 y 1979. Resultados de la parte argentina. Contrib Inst Nac Invest Desarr Pesq (Mar del Plata). No 383: 128-135.

Le Pennec M, Paugam A, Le Pennec G. 2003. The pelagic life of the pectinid Pecten maximus - a review. ICES J Mar Sci. 60: 211-233.

Martos P, Piccolo MC. 1988. Hydrography of the Argentine continental shelf between $38^{\circ}$ and $42^{\circ}$ S. Cont Shelf Res. 8: 1043-1056.

Matano RP, Palma ED. 2008. On the upwelling of down welling currents. J Phys Oceanogr. 38: 2482-2500.

Ministerio DE Agroindustria. 2016. Exportaciones e importaciones pesqueras - 2015. Subsecretaria de Pesca y Acuicultura, Dirección de Economía Pesquera, $46 \mathrm{p}$.

Navarte M, Pascual M. 2003. Fertilization, larval rearing and post-larval growth of the Tehuelche scallop Aequipecten tehuelchus D’Orb., 1846. Aquaculture. 217: 259-274.

Orensanz JM, Cinti A, Parma AM, Burotto L, Espinosa-Guerrero S, Sosa-Cordero E, Sepúlveda C, Toral-Granda V. 2013. Part I. Latin America rights-based fisheries targeting sedentary resources. En: ORENSANZ JM, SEIJO, $\mathrm{JC}$, editores. Rights-based management in Latin American fisheries. FAO Fisheries and Aquaculture Technical Paper. No 582. p 2-69.

Peck LS, Powell DK, Tyler PA. 2007. Very slow development in two Antarctic bivalve molluscs, the infaunal clam Laternula ellipti$c a$ and the scallop Adamussium colbecki. Mar Biol. 150: 1191-1197.

PEÑA JB. 2001. Taxonomía, morfología y hábitat de los pectínidos iberoamericanos. En: MAEDA-MARTínEZ AN, editor. Los moluscos pectínidos de Iberoamérica: ciencia y acuicultura. México: Limusa. p. 1-25.

Pyen CK, Rho YG. 1978. Studies on the early development and spat collection of Patinopecten yessoensis (Jay) under laboratory conditions. Bull Nat Fish Res Dev Agency. 20: 141-155.

Roman G, Acosta CP, Campos M, SÁnchez JL. 2001b. Interannual variation (1987-1992) in the reproductive cycle of the scallop (Pecten maximus) reared on rafts using the ear-hanging culture technique in O. Grove, Ría de Arousa, NW Spain [resumen]. En: 13th International Pectinid Workshop, Coquimbo, Chile.

Roman G, Martinez G, Garcia O, Freites L. 2001a. Reproducción. En: MAEDA-MARTíneZ AN, editor. Los moluscos pectínidos de Iberoamérica: ciencia y acuicultura. México: Limusa. p 27-59.

SASTRY AN. 1979. Pelecypoda (exluding Ostredae). En: GIESE AC, PEARse JS, editores. Reproduction of marine invertebrates, Vol. V. Molluscs: pelecypods and lesser classes. Nueva York: Academic Press. p 113-292.

Schejter L, Bremec C, Waloszek D, Escolar M. 2010. Recently settled stages and larval developmental mode of the bivalve Zygochlamys patagonica and Hiatella meridionalis in the Argentine Sea. J Shellfish Res. 29 (1): 63-67.

Schwartz M, Campodónico S, López A. 2016. Metodología de traslado a bordo y acondicionamiento en acuarios de vieira patagónica (Zygochlamys patagonica). Inf Invest INIDEP $\mathrm{N}^{\circ} 49 / 2016.10 \mathrm{p}$.

Stokesbury KDE, O'Keefe, CE, Harris BP. 2016. Fischeries sea scalop, Placopecten magellanicus. En: Shumway SE, Parsons GJ, editores. Scallops: biology, ecology, acuaculture and fisheries. Developments in aquaculture and fisheries science, Vol. 40. Elsevier. p. 869897.

TAYlor JE, Gunn, B, Williams, P, Mcnicoll I. 1993. An investigation of techniques for the hatchery and nursery rearing of the king scallop, Pecten maximus (L.). Proceedings of the 
9th International Pectinid Workshop, Nanaimo, Vol. 2. p. 104-107.

Tremblay MJ, Sinclair MM. 1988. The vertical and horizontal distribution of sea scallop (Placopecten magellanicus) larvae in the Bay of Fundy, Canada, in 1984 and 1985. J Northwest Atl Fish Sci. 8: 43-54.

Tremblay MJ, Sinclair M. 1992. Planktonic sea scallop larvae (Placopecten magellanicus) in the Georges Bank region: broad scale distribution in relation to physical oceanography. Can
J Fish Aquat Sci. 49: 1597-1615.

Uriarte I, Rupp G, Abarca A. 2001. Producción de juveniles de pectínidos iberoamericanos bajo condiciones controladas. En: MAEDAMARTínEZ AN, editor. Los moluscos pectínidos de Iberoamérica: ciencia y acuicultura. México: Limusa. p. 147-171.

Recibido: 04-05-2018

Aceptado: 17-10-2018 